\title{
COVID-19 and Stroke: An Emerging Association
}

\section{Carlo Emanuele Saggese}

Unità Terapia Neurovascolare, Ospedale "F. Spaziani", Frosinone, Italy
Dear editor,

We have read with interest the letter of Finsterer and Scorza [1], which commented on our article, regarding a case of stroke and thromboses at different sites in a COVID-19 positive patient. We want to answer the observations that have been raised.

Carotid US was not done since the patient underwent angio CT scan that studied not only intracranial vessels, but also carotid and vertebral arteries since their origin, including aortic arch. Multimodal MRI was not done. However, this patient underwent 4 CT scans: the second one showed the appearance of the acute ischemic lesion (not present at the first CT scan), the third showed the hemorrhagic transformation of the lesion and the fourth its stability, so that the acuity and the dynamics of the pathology had been adequately investigated.

The patient underwent a $72 \mathrm{~h}$ ECG continuous recording and transthoracic echocardiogram that did not show elements which could support a cardioembolic genesis of stroke. There was no clinical, ECG, or US evidence for Tsakotsubo syndrome. Our investigations did not support a cardioembolic pathogenesis. Consequently we considered, until proven otherwise, the atherothrombotic pathogenesis as the more likely.

During the hospital period the patient underwent 2 thorax CT scans, which did not reveal signs of suspicion for a neoplasm; however, given the multiple thromboses at different sites, a paraneoplastic syndrome could have been suspected; actually, after the discharge the patient underwent a total body CT scan that did not show neoplastic lesions. We reported 2 different ways through which SARS$\mathrm{CoV}-2$ may penetrate the central nervous system: it may be

karger@karger.com

(c) 2021 S. Karger AG, Basel

www.karger.com/ced

Karger either through the olfactory nervous terminations or alternatively through the hematogenous route. Our study was not focused on the genesis of dysgeusia in SARS-CoV-2, and we agree that a cytokine storm could contribute to the neurologic involvement of SARS-CoV-2 [1]. Our aim was to show how even milder cases of COVID-19 could be related with stroke, and that these patients for the first time could arrive to physiscian's attention due to a cerebrovascular accident.

We agree that among the patients with SARS-CoV-2, those with higher vascular risk factors are more likely affected by stroke. As well as other viruses, SARS-CoV-2 may represent a trigger that can favor stroke in patients with high vascular risk. However, further recent evidence supported the role of SARS-CoV-2 in endothelial disfunction and induction of a procoagulative state $[2,3]$. We speculated how COVID-19 may be related with stroke; however, we are conscious that at the moment, it is not possible to sustain a certain and direct contribution of SARS-CoV-2 in stroke pathogenesis and that further evidence is needed.

\footnotetext{
References 1 Finsterer J, Scorza FA. Ischemic stroke in COVID-19 patients may be incidentally but not causally related to the infection. Cerebrovasc Dis. 2020.

2 Evans PC, Ed Rainger G, Mason JC, Guzik TJ, Osto E, Stamataki Z, et al. Endothelial dysfunction in COVID-19: a position paper of the ESC Working Group for Atherosclerosis and Vascular Biology, and the ESC Council of Basic Cardiovascular Science. Cardiovasc Res. 2020 Dec 1;116(14):2177-84.

3 Spence JD, de Freitas GR, Pettigrew LC, Ay H, Liebeskind DS, Kase CS, et al. Mechanisms of stroke in COVID-19. Cerebrovasc Dis. 2020; 49(4):451-8.
} 